Sustainable cropping pattern in North Iran: application of fuzzy goal programming Peer-reviewed author version

Joolaie, Ramtin; Sarvestani, Ahmad Abedi; Taheri, Fatemeh; VAN PASSEL, Steven \& AZADI, Hossein (2017) Sustainable cropping pattern in North Iran: application of fuzzy goal programming. In: Environment, development and sustainability, 19(6), p. 2199-2216.

DOI: $10.1007 / \mathrm{s} 10668-016-9849-9$

Handle: http://hdl.handle.net/1942/25686 


\title{
Sustainable Cropping Pattern in North Iran: Application of Fuzzy Goal \\ Programming
}

\begin{abstract}
Due to the important important role that the application of mathematical programming models have in determining optimal cropping patterns, this research presents a sustainable cropping pattern that considers selected economic, environmental, and social goals together. Using a random sampling method, a sample size of 168 farmers was selected in the Sari County, Iran. Our results showed that economic, self-sufficiency, environmental, and social goals have a distinctly different impact on cropping pattern performance. Compared to the current cropping pattern, the gross margins for economic and social goals increased by nearly $11 \%$ and $2 \%$, respectively, and the gross margins for self-sufficiency and environmental goals decreased by nearly $2 \%$ and $36 \%$. Interestingly, it has been found that the performance of the current cropping pattern has an average positive impact of 6\% if economic, self-sufficiency, environmental, and social (employment) goals are realized simultaneously.
\end{abstract}

Keywords: Sustainable Agriculture; Environmental Development; Crop Planning; Fuzzy Sets.

\section{Introduction}

Because agriculture is the most stable sector in economy, it has an important role in securing food safety and the general welfare of the people in many countries. Fertile lands and agricultural resources, however, are limited and determining the optimal cropping patterns for a given area needs to be based on the sustainable agriculture goals at both the individual (farmer) and national levels. Within the sustainable agriculture approach, the connection between environmental, social, 
and economic dimensions is expanding on both of these levels (Sharifzadegan et al., 2011). A long-term sustainable agriculture enhances the environmental quality and the resource base that agriculture depends on; provides for the basic food and fiber needs of the human population, and enhances the quality of life for farmers and society as a whole; all of which is economically viable at both farmer and national levels. Sometimes, the economic goals do not coincide, but rather contradict each other. At the farmer level, the optimum cropping pattern is an important factor that affects the farmer's profit. In contrast, policy makers at the national level seek to achieve selfsufficiency through the production of strategic crops (e.g., wheat, barley). Therefore, the optimal allocation of inputs can not only satisfy one of the most important economic purposes of a country, but it can increase farmers' income (Lu et al. 2003; Feng et al. 2006; Mohaddes and Mohayidin 2008; Beynon and Munday 2008; Pala and Sahu 2008; Duke et al. 2012; Girard et al. 2015).

Agricultural planning problems generally contain multiple goals that might conflict in nature and the environment. It is, therefore, not possible to maximize or minimize all or some of these goals simultaneously, while certain goals may be achieved at the cost of others. Thus, some compromises between the goals are required in order to obtain a "satisfactory solution" in the decision making process. Goal programming (GP) is a technique that was initially proposed by Charnes and Cooper (1961); later on, Lee (1972), Ignizio (1976), and others contributed significantly to the improvement of this technique. GP is a useful tool when dealing with the problems of having multiple and conflicting objective functions, as well as for obtaining a satisfactory solution that, given the constraints of the problem, comes closest to meeting the stated goals. It is commonly used to handle multi criteria situations within the linear programming framework. Multi criteria decision techniques have the potential to take into account the conflicting, multidimensional, incommensurable, and uncertain effects of decisions explicitly (Ananda and Herath, 2003). 
Moreover, the multi criteria decision can be used in interactive decision making processes, as interaction becomes a dialogue where the model responds to an initial set of preferences and tradeoffs (Herath and Prato, 2006). Several authors (Lee 1972; Goodman 1974; Palmini 1982; Romero 1991; Sharma et al. 2003) have successfully implemented the GP technique in order to solve different decision making problems (Sharma et al. 2007).

Generally within a GP, the parameters of the problems need to be precisely defined. Yet, in most agricultural planning problems lack accurate data, and the values of some of the parameters may be not clearly known. Instead, these parameters are defined in a fuzzy sense; this occurs for example, when there is no accurate data about the amount of available resources. In order to successfully tackle such problems, fuzzy goal programming (FGP) could be the best technique as FGP has been broadly used in agricultural planning in the past (Charnes et al. 1979; Sinha et al. 1988; Pal and Moitra 2003; Biswas and Pal 2005; Sharma et al. 2007; Sharma and Jana 2009; Chowdhury and Al-Zahrani 2014).

There is a large degree of uncertainty when it comes to measuring sustainability in agriculture since sustainable agriculture involves many different elements and dimensions that affect the function and integrity of agroecosystems. The nature of this vagueness and uncertainty is said to be fuzzy, rather than crisp, especially when subjective assessments are involved in the decision making process. In this study, in order to consider uncertainty, fuzzy concept was used. Sugianto (1999) and Azadi et al. (2009) pointed out that the fuzzy set theory has been known to be an effective approach when coping with uncertainty or inexact statements.

In the FGP, several goals can not only be achieved, but both objectives and constraints can be either crisp or fuzzy. In other words, it is possible to consider non-deterministic goals as well as the possibility to prioritize goals. In recent years some studies employed the FGP approach in 
order to determine optimum cropping patterns (Biswas and Pal 2005; Sharma and Jana 2009; Soltani et al. 2011).

Biswas and Pal (2005) applied FGP in the case of a land use planning problem in an agricultural system in which the utilization of total cultivable land, supply of productive resources, expected profit, and expected production of various crops were defined fuzzily. In their research, they presented how FGP can efficiently be used for modeling and solving land-use planning problems in agricultural systems for optimal production of several seasonal crops in a planning year.

Sharma et al. (2007) presented a FGP model for optimal allocation of land under cultivation and proposed an annual agricultural plan for different crops. They demonstrated that when multiple conflicting objectives are involved, the FGP approach is a superior technique over single objective criterion. In addition, the model developed provided the best possible solution that resolvedthe model constraints.

Hassan and Ahmad (2006) selected the irrigated areas of the Punjab province in order to determine the optimum cropping pattern under various price options using a liner programing (LP) model. Crops included in the models were wheat, basmati rice, IRRI rice, cotton, sugarcane, maize, potato, gram, and mong/mash. They reported that the irrigated agriculture in Punjab is more or less operating at the optimal level.

Abadi et al. (2009) studied the optimal cropping pattern in Taybad, Northeast Iran. They concluded that fuzzy multi-objective fractional programming (FMOLFP) models can be used as effective tools for developing optimal cropping patterns when, in addition to economic, environmental goals should be noticed.

Soltani et al. (2011) also applied FGP in order to determine optimal cropping patterns. The purpose of their study was to find the cropping pattern in the Bardsir region of the Kerman province in 
Iran, that could maximize crop production and net return while minimizing the need to employ labor, water, and machinery. The results indicated that the tolerance level only occurred for the net profit goal but the crop production, labor, and water requirement as well as machine utilization completely achieved their aspiration levels.

The optimal cropping patterns based on individual goals were presented and followed by using a multi-objective fuzzy goal programming, emphasizing the use of conservation tillage methods in the Darab region. Individual goals consisted of maximizing the gross margin, food security, minimizing water consumption, and the application of nitrogen fertilizer. The results showed that in a multi-objective cropping pattern, gross margin and food security increased by $23.5 \%$ and $6.1 \%$, while water and energy consumption decreased by $4 \%$ and $5.1 \%$, respectively, as compared to the current cropping pattern (Erfanifar et al. 2014).

This study presents a sustainable cropping pattern that considers different goals in different categories. However, there is a lack of comprehensive studies that consider selected economic, environmental, and social goals together. As a result, this study tried to fill this gap by putting the categories in one model, the results of which may guide decision makers to find comprehensive sustainable cropping patterns. Accordingly, the following section provides an introduction to this region of study and the fuzzy goal programming methodology. In the next section, each scenario and its result will be discussed. In the conclusion section, the suggested model (scenario number 5) will be compared to models of other scenarios.

\section{Methodology}

\subsection{Study area and sampling}


The Mazandaran province, with an area of $23770.18 \mathrm{~km}^{2}$, is located in the north of Iran. This province is placed south of the Caspian Sea and therefore has a humid climate, which is very suitable for agriculture and gives this province an important socio-economic status. The four largest counties of the province include Sari, Nur, Tonekabon, and Amol, among which Sari was selected to conduct this study. The required data (i.e., production of crops, cultivated lands for each crop, water consumption, amount of fertilizers and pesticides, labor, requirement of machinery and cash requirement for all crops) was gathered from Iran's Ministry of Agriculture. The main crops of this region are rice, rain-fed wheat, rain-fed barley, rain-fed rapeseed, and clove and the total area of land under cultivation in this province is around 50,560 hectares.

The population of this study consisted of farmers in the Sari County, where data was collected using a survey research method. Assuming that the distribution of the sample is approximately normal, the parameter is quantitative and continuous and the population size is unknown, the following formula can be used to calculate the size of the sample:

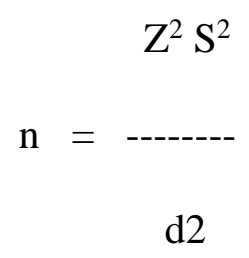

Where:

$\mathrm{n}$ is the size of sample;

$\mathrm{Z}$ is the $\mathrm{z}$-statistics for the desired level of confidence;

$\mathrm{S}$ is the population standard deviation;

$\mathrm{d}$ is the half width of the desired interval. 
In this study the population standard deviation was obtained from pretest sampling, and d is $5 \$$ per hectare and $\mathrm{Z}$ for 95 percent confidence interval is 1.96 . The sample was selected through a random sampling method.

\section{[insert Fig 1]}

\subsection{Method}

In the FGP, the aspiration level of different objectives is always fuzzy, while the amount of right hand side constraints can be either fuzzy or non-fuzzy, depending on the decision making environment. The use of fuzzy set theory in goal programming was first introduced by Narasimhan (1980). It was further developed by Hannan (1981 and 1982), Ignizio (1982), Rubin and Narasimhan (1984), Tiwari et al. (1986 and 1987), Chen (1994)) and others. Chen and Tsai (2001) presented an intensive review of FGP and according to Biswas and Pal (2005), the general form of the FGP model is as follows:

$\operatorname{Find} X\left(x_{1}, x_{2}, x_{3}, \ldots, x_{n}\right)$

So as to satisfy

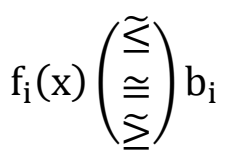

Subject to:

$\mathrm{AX}\left(\begin{array}{l}\leq \\ = \\ \geq\end{array}\right) \mathrm{B}, \quad \mathrm{X} \geq 0$

Where 
$f_{i}(x)$ is $i$-th fuzzy goal (linear or nonlinear) and $b_{i}$ is the aspiration level related to $f_{i}(x)$. Symbols $\Xi, \cong, \widetilde{\Xi}$ represent the goals' fuzziness and $\mathrm{AX}\left(\begin{array}{l}\leq \\ = \\ \geq\end{array}\right)$ B is the reflection of the absolute constraint. In the fuzzy decision-making environment, fuzzy goals are defined by their membership functions which their types depend on the type of the goals. The allowed tolerable range for the fuzzy goals to achieve aspiration levels with different types of limits such as $\widetilde{\geq} \widetilde{\subseteq}, \cong$ will be defined by $\left(b_{i}-t_{i}, b_{i}\right),\left(b_{i}, b_{i}+t_{i}\right),\left(b_{i}-t_{i}, b_{i}+t_{i}\right)$ respectively, and $\left(b_{i}-t_{i}\right)$ and $\left(b_{i}+t_{i}\right)$ are respectively the lower and the upper tolerable range. If $t_{i}$ represents tolerable changes for the aspiration level of $\mathrm{b}_{\mathrm{i}}$, then the membership function corresponding to the fuzzy objective, $\mu_{i}(x)$, is defined as follows:

For $\cong$ fuzzy goals:

$$
\mu_{i}(x)=\left\{\begin{array}{ccc}
1 & \text { if } & f_{i}(0)=b_{i} \\
\frac{\left(b_{i}+t_{i}\right)-f_{i}(0)}{t_{i}} & \text { if } & b_{i}<f_{i}(0) \leq b_{i}+t_{i} \\
\frac{f_{i}(0)-\left(b_{i}-t_{i}\right)}{t_{i}} & \text { if } & b_{i}-t_{i} \leq f_{i}(0)<b_{i} \\
0 & \text { if } & f_{i}(0)<b_{i}-t_{i}, f_{i}(0)>b_{i}+t_{i}
\end{array}\right\}
$$

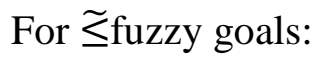

$$
\mu_{i}(x)=\left\{\begin{array}{cc}
1 & \text { iff } f_{i}(0) \leq b_{i} \\
\frac{\left(b_{i}+t_{i}\right)-f_{i}(0)}{t_{i}} & \text { if } b_{i}<f_{i}(0) \leq b_{i}+t_{i} \\
0 & \text { iff } f_{i}(0)>b_{i}+t_{i}
\end{array}\right\}
$$

And for $\cong$ fuzzy goals: 


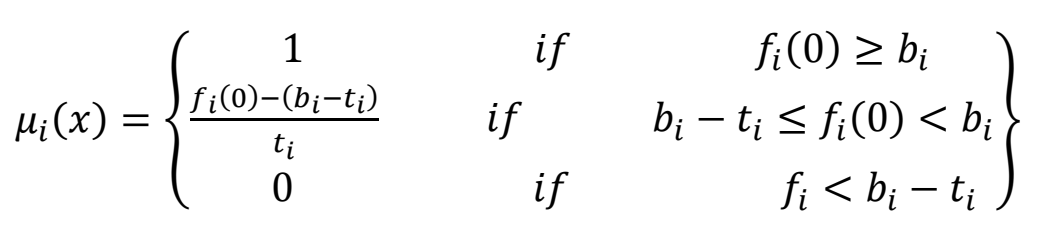

In the FGP, achieving a fuzzy goal to its aspiration level is equivalent to achieving a corresponding membership function to its maximum amount (at 1). Membership functions change to membership goals by determining the maximum amount as the optimum level, and adding positive and negative deviation variables (For example $\mathrm{n} 1$ and $\mathrm{p} 1$ for first scenario) for each of their goals. Then, undesirable deviation variables will be minimized in an objective function in order to achieve the aspiration level (Kohansal and Mohammadian 2007; Erol et al. 2011). Thus, the amount of membership function will be calculated by subtracting achieved undesirable deviations from one. In this study, the cropping pattern model for Sari was formulated with 45 absolute constraints and 11 decision variables for each crop. The absolute constraints included in the analysis are: land (1 constrain), different fertilizers (3 constrains), different pesticides (3 constrains), labor (12 constrains; one for each month), water (12 constrains; one for each month), machinery (12 constrains; one for each month), capital (1 constrain) and irrigated land (1 constrain). The models were estimated using Lingo (Version 11). Tables 1 and 2 present variables used in the model.

[insert Table 1]

[insert Table 2]

Accordingly, different scenarios were developed:

1- Scenario 1 (economic goal)

As the economic goal is a maximizing goal, the membership function is extracted from equation number 4. For instance, in the first scenario; the current total gross margin in Sari County was 
considered as the lowest tolerable range limitation (59.8328). Furthermore, the desire goal was considered as a $20 \%$ increase in the current total gross margin value $(20 \% * 59.8323=11.9666)$. Therefore, the aspiration level was equal to $(59.8328+11.9666=71.7994)$.

$\mu_{1}: \frac{\sum_{i=1}^{11} S_{i} X_{i}-59.8328}{11.9666}+n_{1}-p_{1}=1$

2- Scenario 2 (self-sufficiency goal)

As the self-sufficiency goal is a maximizing goal, the membership function is extracted from equation number 4.

$$
\begin{aligned}
& \mu_{2}: \frac{1^{*} X_{1}-15400}{5696}+n_{2}-p_{2}=1 \\
& \mu_{3}: \frac{1^{*} X_{2}-5089}{1882}+n_{3}-p_{3}=1 \\
& \mu_{4}: \frac{1^{*} X_{3}-4358}{379}+n_{4}-p_{4}=1 \\
& \mu_{5}: \frac{1^{*} X_{10}-3348}{500}+n_{5}-p_{5}=1 \\
& \mu_{6}: \frac{1^{*} X_{11}-7197}{459}+n_{6}-p_{6}=1
\end{aligned}
$$

3- Scenario 3 (environmental goal)

As the environmental goal is a minimizing goal, the membership function is extracted from equation number 3.

Minimizing the use of fertilizers 


$$
\begin{aligned}
& \mu_{7}: \frac{9572-\sum_{i=1}^{11} F_{i} X_{i}}{670}+n_{7}-p_{7}=1 \\
& \mu_{8}: \frac{23530-\sum_{i=1}^{11} A Z_{i} X_{i}}{1647}+n_{8}-p_{8}=1 \\
& \mu_{9}: \frac{1460-\sum_{i=1}^{11} P_{i} X_{i}}{102}+n_{9}-p_{9}=1
\end{aligned}
$$

\section{Minimizing use of pesticides}

$$
\mu_{10}: \frac{99-\sum_{i=1}^{11} A_{i} X_{i}}{1}+n_{10}-p_{10}=1
$$

$$
\mu_{11}: \frac{514-\sum_{i=1}^{11} H_{i} X_{i}}{5}+n_{11}-p_{11}=1
$$

$$
\mu_{12}: \frac{26-\sum_{i=1}^{11} G H_{i} X_{i}}{0.3}+n_{12}-p_{12}=1
$$

Minimizing the use of water

$$
\begin{gathered}
\mu_{13}: \frac{68303-\sum_{i=1}^{11} W_{i} X_{i}}{635}+n_{13}-p_{13}=1 \\
\mu_{24}: \frac{68303-\sum_{i=1}^{11} W_{i} X_{i}}{635}+n_{24}-p_{24}=1
\end{gathered}
$$

4- Scenario 4 (social goal) 
As the social goal is a minimizing goal, the membership function is extracted from equation number 3.

$$
\begin{aligned}
& \mu_{25}: \frac{\sum_{i=1}^{11} l_{i} X_{i}-909}{13}+n_{25}-p_{25}=1 \\
& \mu_{36}: \frac{\sum_{i=1}^{11} l_{i} X_{i}-909}{13}+n_{36}-p_{36}=1
\end{aligned}
$$

5- Scenario 5 (Integration of scenario 1 to 4 )

The aspiration levels of fuzzy goals and their tolerable range are shown inTable3.

[insert Table 3]

\section{Results and discussion}

As mentioned in the research methodology, the model of this study was solved in five scenarios. The explanation of the scenarios is as follows:

\subsection{Scenario 1 (economic goal)}

3.1.1Maximizing the gross margin

The gross margin of various products per hectare was obtained by multiplying the yield of each product at its market price minus its variable cost per hectare. The current total gross margin of Sari County was considered to be witihin the lowest tolerable range limitation. Furthermore, the desire goal was considered to be a $20 \%$ increase in the current total gross margin value. This amount was determined according to the views of the local farmers. 
The results of the fuzzy models are shown in Table 4. Accordingly, results of the fuzzy model for scenario 1 , in which the profit was maximized, showed that the gross margin increased to about 6,897,497 USD, with regard to the actual cropping pattern. In other words, in this scenario, the gross margin increases by $11.11 \%$ based on the actual cropping pattern. Table 5 presents the value of membership functions and undesirable deviations. According to the results, the increased profit is due to the use of high quality rice and high rice yields in the cultivated area through double cropping said high quality rice, as well as double cropping clover and rapeseed.

[insert Table 4]

[insert Table 5]

\subsection{Scenario 2 (self-sufficiency goal)}

\subsubsection{Achieving self-sufficiency}

According to the Iran's Constitutional Law, self-sufficiency and food security is incredibly crucial. In accordance with the fifth development plan, one of the government's goals is to achieve selfsufficiency in the production of main agricultural products such as wheat, barley, maize, rice, oil seeds, sugar beet, and sugar cane. Among these products, planting wheat, barley, rice, and rapeseed is possible in the study area. The current cultivation area of these crops in the county was considered to be the lowest tolerable range for this goal. Accordingly, in order to achieve the aspiration level, the coefficient of self-sufficiency was examined. Furthermore, the aspiration level was considered by increasing the cultivated area of these crops, at least in order to promote the country's self-sufficiency coefficient to the maximum level (100\%). The self-sufficiency ratio is 
an index computed by dividing the amount of production to the domestic consumption of each product. This index is also used as an indicator of self-sufficiency for each product.

Results obtained from the fuzzy model of the second scenario in which self-sufficiency in agricultural products was considered show that watermelon and all rice double cropping have been eliminated from the current cropping pattern. The cultivated areas of the high yield rice, rain-fed rapeseed, rain-fed barley, and rain-fed wheat increased to 37, 9, 21 and 6\%, respectively. In contrast, the cultivated areas of the high quality rice decreased to around $12 \%$. In this scenario, the cultivated areas of the high yield rice, rain-fed rapeseed, rain-fed barley and rain-fed wheat met their aspiration levels towards achieving the country's goal of self-sufficiency. Furthermore, the membership functions of theses fuzzy goals obtained their maximum value (one), except for the high quality rice, which not only did not reach the aspiration level, but had a long way to go to achieve self-sufficiency (Table 6). This result was expected since rice, canola, wheat, and barley are listed as the main crops of Iran, therefore, self-sufficiency in these crops is considered as the goal of scenario 2 .

[insert Table 6]

\subsection{Scenario 3 (environmental goal)}

\subsubsection{Minimizing the use of fertilizers}

In recent years the misconception that excessive use of chemical fertilizers can lead to the increased production, has been the cause of devastating environmental impacts on soil and ground water. For this reason, decreasing the use of fertilizers in order to approach the international standards should be a goal of agricultural managers. In accordance with Article 143 of Iran's fifth Five-Year Development Plan (FFDP) (2011-2015), the use of fertilizers should decrease by 35\% 
through the promotion of organic manures and bio-fertilizers. Thus, the average reduction rate of $7 \%$ per year was considered in this study. Accordingly, the desired goal is a decline of $7 \%$ in the use of each type of the phosphate, nitrogen, and potassium fertilizers, respectively.

The results of the fuzzy model for the third scenario, in which environmental goals were included, show that in the case of the phosphate fertilizer membership function, the value reached the maximum state at one, whereas the amount of the membership function for nitrogen and potassium fertilizers reached to the threshold of their aspiration levels (Table 7). Based on the limit of the cultivable lands in Iran, the model has limitations for decreasing the total cultivated area; accordingly, some of the goals, such as decreasing nitrogen and potash fertilizers, could not meet their aspiration levels.

[insert Table 7]

3.3.2 Minimizing the use of pesticides (herbicides, insecticides, fungicides)

Over use of pesticides along with increasing yields, cause serious damage to natural resources and the environment. Therefore, reducing the use of pesticides should be one of the principal environmental objectives of farm managers. Based on Article 28 of the Plant Protection Organization and Article 34 of the FFDP, this organization is responsible for monitoring pesticide residues in agricultural production. Therefore, in order to produce healthy and organic products, corresponding with duties of Iran's Fifth Development Plan, a one percent reduction in pesticide usage was considered in this study. Furthermore, the aspiration level was considered to be reducing one percent in the use of each type of the chemical pesticides. 
The third goal of reducing the use of herbicides reached the threshold of its aspiration level. Reduction of insecticides and fungicides was completely successful, and the value of the membership function for these fuzzy goals reached its maximum goal (one).

\subsubsection{Minimizing the use of water}

In the current economic theories, the concept of sustainability is used in planning and community development. Sustainability of water resources is one of the most important aspects of economic stability. Since Iran is located in an arid region, it is very important to take the interests of future generations into account according to the principle of sustainable use in regard to water resources. In Iran's Environment Document, a 13\% reduction in water use in agriculture is predicted by 2025 ( $0.93 \%$ in each year). Thus, in this study, the 12 -month goal is to develop a $0.93 \%$ reduction in the agricultural water consumption in Sari County.

Moreover, regarding to the 12-month fuzzy goal of decreasing water consumption, the membership function reached its maximum level (one) in a majority of the months. Water consumption could not be decreased by the membership only in the first month of summer (Table 7).

\subsection{Scenario 4 (social goal)}

Employment in today's world has attracted a lot of attention from policy makers, government officials, and experts. Consequently, the current unemployment rates and its consequences are fundamental problems in Iran's economy. According to FFDP, a 1.4\% increase in employment has 
been considered. Thus, in this study, the 12 -month goal is to develop a $1.4 \%$ increase in employment in the agriculture of Sari County.

The result of the FGP model for scenario 4 illustrates that the goal of increasing employment opportunities in certain months, such as the second and third months of spring, the second month of summer, and the second month of fall, was almost successful and its membership function for this goal was near its maximum level (one). In the rest of the months, increasing employment was completely successful (Table 8).

[insert Table 8]

\subsection{Scenario 5 (Integration of scenario 1 to 4)}

In this scenario, the fuzzy goals of scenario 1 to 4 were simultaneously applied in the model. The aspiration levels of fuzzy goals and their tolerable range are shown in Table 3. In the fuzzy models of this study, the negative and positive deviations from the aspiration goal are shown with " $\mathrm{n}$ " and "p”, respectively, and W represents the weight of each goal. The weight of the goal of maximizing the gross margin, W1, the weight of goals to achieving self-sufficiency intended crop, W2 to W6, weight of goals to minimize the use of phosphate, nitrogen and potassium fertilizers, W7 to W9, weight of goals to minimize the use of herbicides, insecticides and fungicides, W10 to W12, weight

of goals to minimize the use of water per each month, W13 to W24, and weight of goals to increase the employment in each month, W25 to W36, were considered (Table 9).

Because the aim was to have equal weight for economic, self-sufficiency, environmental, and social goals, and since we only had one membership function for an economic scenario, one was 
chosen for its weight. Consequently, in the second scenario we had five membership functions and the weight for each one was 0.2; this pattern was obeyed by all other scenarios.

[insert Table 9]

If the government seeks to achieve all the goals simultaneously, it will need to consider the model that was formed from scenario 5. As discussed in the previous section, other goals exist alongside the gross margin in scenario 5. Consequently, the gross margin decreases when compared to the result of scenario 1 (the gross margin maximization scenario). Comparing the results of the cultivated area of different crops also shows that the fifth scenario seeks to provide an intermediate solution regarding all its goals.

According to this model, the goals of the sustainable development of agriculture, like $7 \%$ decreases in potash fertilizer and percentage $1 \%$ reduction in using herbicide and insecticide, could be met. The goal of a $0.93 \%$ reduction in water consumption per month could be met if the first month of summer is excluded. Furthermore, the value of membership function and undesirable deviation was obtained and was equal to one and zero, respectively (Table 10).

[insert Table 10]

This study quantifies the usefulness of cropping pattern optimization using the FGP model. Similarly, in recent years, some studies have employed the FGP approach by considering a variety of goals in order to determine optimum cropping patterns (Biswas and Pal 2005; Sahoo et al 2006; Sharma and Jana 2009). The results show that the current cropping pattern is economically inefficient and that we lose $11 \%$ of the gross margin. Accordingly, the optimum cropping pattern for farmers can improve their income. This result is similar to the studies by Mohammadi et al. (2012) and Soltani et al. (2011) who found a 20.6\% and 26.1\%, respectively, improvement in gross margins compared to the current cropping pattern. Moreover, Mohaddes and Mohayidin (2008) 
applied a fuzzy multi-objective mathematical programming model to the Atrak watershed agricultural development plan in Iran. Results of their model indicated that, when compared with the current cropping structure, the implementation of the optimum cropping pattern can increase profit and employment, and decrease soil erosion significantly.

\section{Conclusion}

The FGP approach to agricultural planning when determining optimal cropping patterns demonstrated in this study, provides a new perspective into the way of analyzing multiple goals such as maximizing crop production, maximizing overall profit, minimizing labor expenditures, water requirements and others, in an imprecise decision-making environment. The main advantage of the proposed approach is obtaining a more satisfactory solution in the decision making process by compromising certain ones among the multiple goals.

Self-sufficiency has a small negative impact on the current gross margin $(-1.64 \%)$. Therefore, considering self-sufficiency will diminish farmers' income and consequently their welfare. If policy makers intend to realize self-sufficiency policies through cropping patterns, farmers should be supported for their loss.

Self-sufficiency in the high yield rice, rapeseed, wheat, and barley can be completely achieved. Cultivated areas of the high quality rice decreased compared to the current situation and is replaced by high yield rice. Generally, achieving $100 \%$ self-sufficiency for rice is not expected as Iran is obviously located in semi-arid region with water availability limitations. A possible solution could be the development of less water intensive rice varieties by the Rice research institute of Iran. Policy makers can stimulate agro-technological development in order to improve self-sufficiency 
as well. Realizing full self-sufficiency for all crops is impossible with the current technology and in certain specific cases, it would be very costly.

A drastic decrease in the gross margin is observed if environmental goals are maximized. With regard to the suggested cropping pattern in this scenario, most of the cultivated area has been allocated for rain-fed barley, which has minimum uses for water, pesticides, and fertilizers. The results also show that, the third scenario, which considers only environmental goals, will lead us to unrealistic results.

In the fourth scenario, which considers increasing employment as a social goal, an increase in the gross margins compared to the current cropping pattern is observed. This increase is lower compared to the economic scenario. In other words, considering employment in cropping patterns as a goal will increase farmers' profits, even though this pattern is not optimum from an economic point of view. However, in this study, employment is considered as a social goal, while social aspects, in general, have many dimensions and impacts (such as land conflicts, water conflicts and the like). Further research can try to incorporate these aspects.

Integrating all such aspects can be seen as sustainable optimum. Though the operationalization of sustainability assessment is essential and several different methods can be used (Van Passel and Meul 2012). Fuzzy Goal Programming (FGP) considers several goals simultaneously and both objectives and constraints can be crisp or fuzzy. As a result, we believe that FGP complements existing approaches to assess sustainability.

Since the results of the proposed model (Scenario 5), with a significant reduction in the current gross margin, are not favorable and will lead to a reduction in the welfare of farmers and their living conditions. It is recommended that policy makers provide support in these situations, such as low-interest credits, guaranteed prices, and cheaper biological pest management for farmers. It 
is notable that in Japan and Korea, both of which have relatively high levels of support within their agricultural policies, agro-environmental schemes have been introduced only relatively recently. While in other countries, such as Mexico and Turkey, limited agricultural policy budgets have been prioritized for other purposes. However, Mexico has a program to encourage sustainable agriculture and Turkey has been introducing a series of initiatives to support organic farming over the last 5 years (OECD, 2009). Agro-environmental measures have been a central feature of EUwide agricultural policy since the mid-1990s. The EU review identifies a range of mechanisms by which environmental issues in agriculture are addressed, including: regulatory requirements, agroenvironmental payments, environmental taxes, tradable rights and quotas, environmental crosscompliance, community based approaches, research, and extension (FAO, 2010).

Also in this model, achieving self-sufficiency in order to produce high-yield rice was ignored and its' cultivated area reached zero. The cultivated areas of the high quality rice increased compared to the current situation. In contrast, self-sufficiency in barley, rapeseed, and wheat is fully achieved. This is because, according to the coefficients of self-sufficiency, achieving selfsufficiency in rice is much harder than for other products. Furthermore, in the model, the reduction in phosphate and potassium fertilizers and fungicide does not occur. The main reason is the presence of conflicting objectives. Therefore, the model could not further decrease the use of fertilizers. Regardless, in this model, it is possible to increase employment opportunities in months with greater need for labor.

\section{Acknowledgement}

The authors wish to thank Ms. Bethany Gardner from the Department of Linguistics, the State University of New York at Binghamton, for her kind help in improving the English of this text. 


\section{References}

Ananda, J., \& Herath, G. (2003). The use of Analytic Hierarchy Process to incorporate stakeholder preferences into regional forest planning. Forest policy and economics, 5(1), 13-26.

Azadi, H., van den Berg, J., Shahvali, M., \& Hosseininia, G. (2009). Sustainable rangeland management using fuzzy Logic: A case study in Southwest Iran. Agriculture, Ecosystems \& Environment, 131(3\&4), 193-200.

Beynon, M.J., \& Munday, M. (2008). Considering the effects of imprecision and uncertainty in ecological footprint estimation: An approach in a fuzzy environment. Ecological Economics, 76 (3), 373-383.

Biswas, A., \& Pal, B.B. (2005). Application of fuzzy goal programming technique to land use planning in agricultural system. Omega, 33, 391-398.

Biswas, A., Dharmar, S., \& Rao, J.R. (1978). Fuzzy goal programming, an additive model. Fuzzy Sets and systems, 24, 27-34.

Charnes, A., Cooper, W.W., Karwan, K.R ., \& Wallace, W.A. (1979). A chance-constrained goal programming model to evaluate response resources for marine pollution disasters. Journal of Environmental Economics and Management, 6 (3), 244-274.

Charnes, A., \& Cooper, W.W. (1961). Management Models and Industrial Application of Linear Programming. New York: John Wiley \& Sons.

Chen, H.K. (1994). A note on a fuzzy goal programming algorithm by Tiwari, Dharmar and Rao. Fuzzy Sets and Systems, 62, 287-290.

Chen, L.H., \& Tsai, F.C. (2001). Fuzzy goal programming with different importance and priorities. European Journal of Operational Research, 133, 548- 556. 
Chowdhury, S., \& Al-Zahrani, M. (2014). Fuzzy synthetic evaluation of treated wastewater reuse for agriculture. Environment, Development and Sustainability, 16 (3), 521-538.

Cochran, W.G. (1977). Sampling techniques (3rd ed.). New York: John Wiley \& Sons.

DOE. (2012). Department of Environment, Collection of rules and regulations, 2nd volume, DOE, Tehran, Iran.

Duke, J.M., Borchers, A.M., Johnston, R.J., \& Absetz, S. (2012). Sustainable agricultural management contracts: Using choice experiments to estimate the benefits of land preservation and conservation practices. Ecological Economics, 74, 95-103.

Erol, I., Sencer, S., \& Sari, R. (2011). A new fuzzy multi-criteria framework for measuring sustainability performance of a supply chain. Ecological Economics, 70 (6), 1088-1100.

Erfanifar, S., Zibaei, M., \& Kasrai, M. (2014). Application of multi-objective fuzzy goal programming to optimize cropping pattern with emphasis on using conservation tillage methods. Journal of Agricultural Economics and Development, 28 (2), 118-124. (In Persian).

FAO. (2010). Natural Resources Management and Environment Department Food and Agriculture Organization of the United Nations. http://www.fao.org/docrep/013/al921e/al921e00.pdf

Feng, H., Kurkalova, L.A., Kling, C.L., \& Gassman, P.W. (2006). Environmental conservation in agriculture: Land retirement vs. changing practices on working land. Journal of Environmental Economics and Management, 52 (2), 600-614.

FFDP. (2010). Iran's 5th Five-Year Development Plan (2011-2015). Available from: http://rc.majlis.ir/fa/law/show/790196

Girard, N., Magda, D., Astruc, J.M., Couix, N., Gross, H., Guyon, J.P., Labatut, J., Poinsot, Y., \& Saldaqui, F. (2015). Analyzing indicators for combining natural resources management and production-oriented activities. Environment, Development and Sustainability, 17 (1), 155-172. 
Goodman, D.A. (1974). A goal programming approach to aggregate planning of production and work force. Management Science, 20 (12), 1569-1575.

Hannan, E.L. (1981). On fuzzy goal programming. Decision Sciences, 12, 522-531.

Hannan, E.L. (1982). Contrasting fuzzy goal programming and fuzzy multicriteria programming. Decision Sciences, 13, 337-339.

Herath, G., \& Prato, T. (2006). Role of multi-criteria decision making in natural resource management. Using multi-criteria decision analysis in natural resource management. Ashgate, Burlington, Vermont, USA, 1-10.

Ignizio, J.P. (1976). Goal Programming and Extensions. Massachusetts: Heath and Company.

Ignizio, J.P. (1982). On the rediscovery of fuzzy goal programming. Decision Sciences, 13, 331336.

Iran’s Ministry of Agriculture Jihad, 2009. Statistical databases of agricultural production.

Kohansal, M.R., \& Mohammadian, F. (2007). Application of fuzzy goal programming to determine the optimal cropping pattern. Journal of Economics and Agricultural, 1(2), 169183. (In Persian).

Lee, S.M. (1972). Goal Programming for Decision Analysis. Philadelphia: Auerbach Publishers.

Lu, Y.C., Teasdale, J.R., \& Huang, W.Y. (2003). An Economic and Environmental Tradeoff Analysis of Sustainable Agriculture Cropping Systems. Journal of Sustainable Agriculture, 22 (3), 25-41. 
Mardani, M., Babaei, M., Saboohi, M., \& Asemani, A. (2013). Determining the optimal cropping pattern using fuzzy goal programming: A case of Khorasan-Razavi province. Journal of Applied Mathematics, 10(1), 4-14. (In Persian).

Mohaddes, S. A., \& Mohayidin, M. G. (2008). Application of the Fuzzy Approach for Agricultural Production Planning in a Watershed: A Case Study of the Atrak Watershed, Iran. AmericanEurasian J. Agric. Environ. Sci., 3(4), 636-648.

Mohammadi, H., Boostani, F., \& Kafilzadeh, F. (2012). Determining the optimal cropping pattern using nonlinear fuzzy multi-objective optimization algorithm: A case study. Journal of Water and Wastewater, 84, 43-55. (In Persian).Narasimhan, R. (1980). Goal programming in a fuzzy environment. Decision Sciences, 11 (2), 325-336.

Narasimhan, R. (1982). On fuzzy goal programming: Some comments. Decision Sciences, 12, 532-538.

OECD. (2009). Agricultural Policies in OECD Countries - Monitoring and Evaluation 2009. Organisation for Economic Co-operation and Development, Paris.

Pal, B.B., \& Moitra, B.N. (2003). Fuzzy goal programming approach to long-term land allocation planning problem in agricultural system: A case study, Proceedings of the fifth International Conference on Advances in Pattern Recognition, Allied Publishers. 441-447.

Palmini, D.J. (1982). The secondary impact of nonpoint-pollution controls: A linearprogramming-input/output analysis. Journal of Environmental Economics and Management, 9 (3). 263-278.

Pala, S., \& Sahu, P.K. (2008). On Assessment of Sustainability of Crops and Cropping System— Some New Measures. Journal of Sustainable Agriculture, 31 (3), 43-54. 
Romero, C. (1991). Handbook of Critical Issues in Goal Programming. Oxford: Pergamon Press.

Rubin, P.A., \& Narasimhan, R. (1984). Fuzzy goal programming with nested priorities. Fuzzy Sets and Systems, 14, 115-129.

Sahoo, B., Lohani, A.K., \& Sahu, R.K. (2006). A fuzzy multi objective and linear programming based management model for optimal land-water-plant system planning. Water Resources Management, 20(6), 931-948.

Sharma, D.K., Ghosh, D., \& Alade, J.A. (2003). Management decision-making for sugar cane fertilizer mix problems through goal programming. Journal of Applied Mathematics and Computing, 13(1-2), 323-334.

Sharma, D.K., Jana, R.K., \& Gaur, A. (2007). Fuzzy goal programming for agricultural land allocation problems. Yugoslav Journal of Operations Research, 17 (1), 31-42.

Sharma, D.K., \& Jana R.K. (2009). Fuzzy goal programming based genetic algorithm approach to nutrient management for rice crop planning. Int. J. Production Economics, 121, 224-232.

Sharifzadegan, M.H., Joudi Gollar, P., \& Azizi, H. (2011). Assessing the strategic plan of tehran by sustainable development approach, using the method of "Strategic Environmental Assessment (SEA)”. International Conference on Green Buildings and Sustainable Cities. Procedia Engineering, 21, 186-195.

Sinha, S.B., Rao, K.A., \& Mangaraj, B.K. (1988). Fuzzy goal programming in multi-criteria decision systems: a case study in agriculture planning. Socio-Economic Planning Sciences, 22(2), 93-101. 
Soltani J., Karbasi A.R., \& Fahimifard, S.M. (2011). Determining optimum cropping pattern using fuzzy goal programming (FGP) model. African Journal of Agricultural Research, 6(14), 33053310.

Tiwari, R.N., Dharmar, S., \& Rao, J.R. (1986). Priority structure in fuzzy goal programming. Fuzzy Sets and Systems, 19, 251-259.

Tiwari, R.N., Dharmar, S., \& Rao, J.R. (1987). Fuzzy goal programming-an additive model. Fuzzy Sets and Systems, 24, 27-34.

Van Passel, S., \& Meul, M. (2012). Multilevel and multi-user sustainability assessment of farming systems. Environmental Impact Assessment Review, 32 (1), 170-180. 
Table 1. Introducing of crops indexes

\begin{tabular}{|l|l|l|l|}
\hline Crops name & index & Crops name & index \\
\hline High quality rice & $\mathrm{i}=1$ & Double cropping high yield rice and rapeseed & $\mathrm{i}=7$ \\
High yield rice & $\mathrm{i}=2$ & Double cropping high yield rice and clover & $\mathrm{i}=8$ \\
Rainfed rapeseed & $\mathrm{i}=3$ & Watermelon & $\mathrm{i}=9$ \\
Clover & $\mathrm{i}=4$ & Rainfed barley & $\mathrm{i}=10$ \\
Double cropping high quality rice and rapeseed & $\mathrm{i}=5$ & Rainfed wheat & $\mathrm{i}=11$ \\
Double cropping high quality rice and clover & $\mathrm{i}=6$ & & \\
\hline
\end{tabular}


Table 2. Variables and parametrs of the model

\begin{tabular}{|l|l|l|l|}
\hline Variable name & index & Variable name & index \\
\hline Herbicide consumption for i-th crop & $\mathrm{Ai}$ & i-th crop cultivated area & $\mathrm{Xi}$ \\
Insecticide consumption for i-th crop & $\mathrm{Hi}$ & i-th crop gross margin & $\mathrm{Si}$ \\
Fungicide consumption for i-th crop & $\mathrm{GHi}$ & Phosphate Fertilizer consumption for i-th crop & $\mathrm{Fi}$ \\
water consumption for i-th crop & Wi & Nitrogen Fertilizer consumption for i-th crop & $\mathrm{AZi}$ \\
Labor use for i-th crop & & potash Fertilizer consumption for i-th crop & $\mathrm{Pi}$ \\
\hline
\end{tabular}


Table 3. Aspiration level of fuzzy goals and their tolerable range allowed

\begin{tabular}{|c|c|c|c|}
\hline \multirow[b]{2}{*}{ Goals } & \multirow{2}{*}{$\begin{array}{l}\text { Aspiration } \\
\text { level }\end{array}$} & \multicolumn{2}{|c|}{ Tolerable range allowed } \\
\hline & & Down & $\overline{\mathrm{Up}}$ \\
\hline Max gross margin(Million USD) & 71.7994 & 59.8328 & Infinitive \\
\hline Self-sufficiency for high quality rice(ha) & 21096 & 15400 & Infinitive \\
\hline Self-sufficiency for high yield rice(ha) & 6971 & 5089 & Infinitive \\
\hline Self-sufficiency rainfed barley(ha) & 3848 & 3348 & Infinitive \\
\hline Self-sufficiency for rainfed rapeseed(ha) & 4737 & 4358 & Infinitive \\
\hline Self-sufficiency rainfed wheat(ha) & 7656 & 7197 & Infinitive \\
\hline Min phosphate fertilizer use(ton) & 8902 & -Infinitive & 9572 \\
\hline Min nitrogen fertilizer use(ton) & 21883 & -Infinitive & 23530 \\
\hline Min potash fertilizer use(ton) & 1358 & -Infinitive & 1460 \\
\hline Min herbicide use (1000 lit.) & 98 & -Infinitive & 99 \\
\hline Min insecticide use (1000 lit.) & 509 & -Infinitive & 514 \\
\hline Min fungicide use (1000 lit.) & 25.97 & -Infinitive & 26 \\
\hline Min monthly water consumption (Million . $\mathrm{m}^{3}$ ) & 67.667 & -Infinitive & 68.303 \\
\hline Increase employment- 1th month(1000 man) & 922 & 909 & Infinitive \\
\hline
\end{tabular}


Table 4. Result of the fuzzy models

\begin{tabular}{|c|c|c|c|c|c|c|c|}
\hline \multirow[b]{2}{*}{ Crop name } & \multirow{2}{*}{$\begin{array}{l}\text { Area } \\
\text { (ha) }\end{array}$} & \multicolumn{6}{|c|}{ Model } \\
\hline & & Current & Scenario 1 & Scenario 2 & Scenario 3 & Scenario 4 & Scenario 5 \\
\hline High quality rice & $\mathrm{X}_{1}$ & 15402 & 3235 & 13507 & 10884 & 6816 & 20598 \\
\hline High yield rice & $\mathrm{X}_{2}$ & 5089 & 0 & 6975 & 0 & 0 & 0 \\
\hline Rainfed rapeseed & $\mathrm{X}_{3}$ & 4358 & 0 & 4737 & 0 & 0 & 4737 \\
\hline Clover & $\mathrm{X}_{4}$ & 3805 & 0 & 0 & 0 & 0 & 0 \\
\hline Double cropping high & $\mathrm{X}_{5}$ & 0 & 5428 & 0 & 0 & 0 & 0 \\
\hline quality rice and rapeseed & & & & & & & \\
\hline Double cropping high & $\mathrm{X}_{6}$ & 0 & 11935 & 0 & 0 & 11935 & 0 \\
\hline quality rice and clover & & & & & & & \\
\hline Double cropping high & $\mathrm{X}_{7}$ & 0 & 0 & 0 & 0 & 0 & 0 \\
\hline yield rice and rapeseed & & & & & & & \\
\hline Double cropping high & $\mathrm{X}_{8}$ & 0 & 0 & 0 & 0 & 0 & 0 \\
\hline yield rice and clover & & & & & & & \\
\hline Watermelon & $\mathrm{X}_{9}$ & 46 & 0 & 0 & 0 & 3786 & 0 \\
\hline Rainfed barley & $\mathrm{X}_{10}$ & 14663 & 29962 & 17686 & 39676 & 28023 & 17284 \\
\hline Rainfed wheat & $\mathrm{X}_{11}$ & 7197 & 0 & 7655 & 0 & 0 & 7656 \\
\hline Sum & $\mathrm{X}_{\mathrm{T}}$ & 50560 & 50560 & 50560 & 50560 & 50560 & 50560 \\
\hline Gross margin & Bil.USD & 62.1001 & 68.9976 & 61.0809 & 40.0274 & 63.5722 & 60.5213 \\
\hline $\begin{array}{l}\text { Change in gross margin } \\
\text { related to current }\end{array}$ & Percent & - & 11.11 & -1.64 & -35.54 & 2.37 & 6.24 \\
\hline
\end{tabular}


Table 5. Value of membership functions and undesirable deviations for scenario 1

\begin{tabular}{cc}
\hline$d_{k}^{-}$ord $d_{k}^{+}$ & $\mu_{k}$ \\
\hline$d_{1}^{-}=0.77$ & $\mu_{1}=0.23$ \\
\hline
\end{tabular}


Table 6. Value of membership functions and undesirable deviations for scenario 2

\begin{tabular}{cccc}
\hline$d_{k}^{+}$or $d_{k}^{-}$ & $\mu_{k}$ & $d_{k}^{+}$or $d_{k}^{-}$ & $\mu_{k}$ \\
\hline$d_{5}^{-}=0$ & $\mu_{5}=1.00$ & $d_{2}^{-}=0.67$ & $\mu_{2}=0.33$ \\
$d_{6}^{-}=0$ & $\mu_{6}=1.00$ & $d_{3}^{-}=0$ & $\mu_{3}=1.00$ \\
& & $d_{4}^{-}=0$ & $\mu_{4}=1.00$ \\
\hline
\end{tabular}


Table 7. Value of membership functions and undesirable deviations for scenario 3

\begin{tabular}{cccccc}
\hline$d_{k}^{+}$or $d_{k}^{-}$ & $\mu_{k}$ & $d_{k}^{+}$or $d_{k}^{-}$ & $\mu_{k}$ & $d_{k}^{+}$or $d_{k}^{-}$ & $\mu_{k}$ \\
\hline$d_{19}^{+}=0$ & $\mu_{19}=1$ & $d_{13}^{+}=0$ & $\mu_{13}=1$ & $d_{7}^{+}=0$ & $\mu_{7}=1$ \\
$d_{20}^{+}=0$ & $\mu_{20}=1$ & $d_{14}^{+}=0$ & $\mu_{14}=1$ & $d_{8}^{+}=0.05$ & $\mu_{8}=0.95$ \\
$d_{21}^{+}=0$ & $\mu_{21}=1$ & $d_{15}^{+}=0$ & $\mu_{15}=1$ & $d_{9}^{+}=0.01$ & $\mu_{9}=0.99$ \\
$d_{22}^{+}=0$ & $\mu_{22}=1$ & $d_{16}^{+}=1$ & $\mu_{16}=0$ & $d_{10}^{+}=0.02$ & $\mu_{10}=0.98$ \\
$d_{23}^{+}=0$ & $\mu_{23}=1$ & $d_{17}^{+}=0$ & $\mu_{17}=1$ & $d_{11}^{+}=0$ & $\mu_{11}=1$ \\
$d_{24}^{+}=0.01$ & $\mu_{24}=0.99$ & $d_{18}^{+}=0$ & $\mu_{18}=1$ & $d_{12}^{+}=0$ & $\mu_{12}=1$ \\
\hline
\end{tabular}


Table 8. Value of membership functions and undesirable deviations scenario number 4

\begin{tabular}{cccccc}
\hline$d_{k}^{+}$or $d_{k}^{-}$ & $\mu_{k}$ & $d_{k}^{+}$or $d_{k}^{-}$ & $\mu_{k}$ & $d_{k}^{+}$or $d_{k}^{-}$ & $\mu_{k}$ \\
\hline$d_{33}^{-}=0$ & $\mu_{33}=1$ & $d_{29}^{-}=0.02$ & $\mu_{29}=0.98$ & $d_{25}^{-}=0$ & $\mu_{25}=1$ \\
$d_{34}^{-}=0$ & $\mu_{34}=1$ & $d_{30}^{-}=0$ & $\mu_{30}=1$ & $d_{26}^{-}=0.01$ & $\mu_{26}=0.99$ \\
$d_{35}^{-}=0$ & $\mu_{35}=1$ & $d_{31}^{-}=0$ & $\mu_{31}=1$ & $d_{27}^{-}=0.02$ & $\mu_{27}=0.98$ \\
$d_{36}^{-}=0$ & $\mu_{36}=1$ & $d_{32}^{-}=0.02$ & $\mu_{32}=0.98$ & $d_{28}^{-}=0$ & $\mu_{28}=1$ \\
\hline
\end{tabular}


Table 9. Weight of goals

\begin{tabular}{|c|c|c|c|c|c|c|c|}
\hline Name & Amount & Name & Amount & Name & Amount & Name & Amount \\
\hline w1 & 1 & w10 & 0.3 & w19 & 0.083 & w28 & 0.083 \\
w3 & 0.2 & w11 & 0.3 & w20 & 0.083 & w29 & 0.083 \\
w4 & 0.2 & w12 & 0.3 & w21 & 0.083 & w30 & 0.083 \\
w5 & 0.2 & w13 & 0.083 & w22 & 0.083 & w31 & 0.083 \\
w6 & 0.2 & w15 & 0.083 & w23 & 0.083 & w32 & 0.083 \\
w7 & 0.3 & w16 & 0.083 & w25 & 0.083 & w34 & 0.083 \\
w8 & 0.3 & w17 & 0.083 & w26 & 0.083 & w35 & 0.083 \\
w9 & 0.3 & w18 & 0.083 & w27 & 0.083 & w36 & 0.083 \\
\hline
\end{tabular}


Table 10. Value of membership functions and undesirable deviations for scenario 5

\begin{tabular}{cccccccc}
\hline$d_{k}^{+}$or $d_{k}^{-}$ & $\mu_{k}$ & $d_{k}^{+}$or $d_{k}^{-}$ & $\mu_{k}$ & $d_{k}^{+}$or $d_{k}^{-}$ & $\mu_{k}$ & $d_{k}^{+}$or $d_{k}^{-}$ & $\mu_{k}$ \\
\hline$d_{28}^{-}=0$ & $\mu_{28}=1$ & $d_{19}^{\mp}=0.001$ & $\mu_{19}=0.999$ & $d_{10}^{+}=0.009$ & $\mu_{10}=0.991$ & $d_{1}^{-}=1$ & $\mu_{1}=0$ \\
$d_{29}^{-}=0.008$ & $\mu_{29}=0.992$ & $d_{20}^{+}=0.001$ & $\mu_{20}=0.999$ & $d_{11}^{+}=0.006$ & $\mu_{11}=0.994$ & $d_{2}^{-}=0.92$ & $\mu_{2}=0.07$ \\
$d_{30}^{-}=0.007$ & $\mu_{30}=0.993$ & $d_{21}^{+}=0.001$ & $\mu_{21}=0.999$ & $d_{12}^{+}=0.013$ & $\mu_{12}=0.987$ & $d_{3}^{-}=1$ & $\mu_{3}=0$ \\
$d_{31}^{-}=0.007$ & $\mu_{31}=0.993$ & $d_{22}^{+}=0.001$ & $\mu_{22}=0.999$ & $d_{13}^{\mp}=0$ & $\mu_{13}=1$ & $d_{4}^{-}=0$ & $\mu_{4}=1$ \\
$d_{32}^{-}=0.008$ & $\mu_{32}=0.992$ & $d_{23}^{+}=0.001$ & $\mu_{23}=0.999$ & $d_{14}^{+}=0.001$ & $\mu_{14}=0.999$ & $d_{5}^{-}=0$ & $\mu_{5}=1$ \\
$d_{33}^{-}=0$ & $\mu_{33}=1$ & $d_{24}^{+}=0.003$ & $\mu_{24}=0.993$ & $d_{15}^{+}=0$ & $\mu_{15}=1$ & $d_{6}^{-}=0$ & $\mu_{6}=1$ \\
$d_{34}^{-}=0$ & $\mu_{34}=1$ & $d_{25}^{-}=0$ & $\mu_{25}=1$ & $d_{16}^{+}=1$ & $\mu_{16}=0$ & $d_{7}^{+}=1$ & $\mu_{7}=0$ \\
$d_{35}^{-}=0$ & $\mu_{35}=1$ & $d_{26}^{-}=0.004$ & $\mu_{26}=0.996$ & $d_{17}^{+}=0.001$ & $\mu_{17}=0.999$ & $d_{8}^{+}=0$ & $\mu_{8}=1$ \\
$d_{36}^{-}=0$ & $\mu_{36}=1$ & $d_{27}^{-}=0.007$ & $\mu_{27}=0.993$ & $d_{18}^{+}=0.001$ & $\mu_{18}=0.999$ & $d_{9}^{+}=1$ & $\mu_{9}=0$ \\
\hline
\end{tabular}




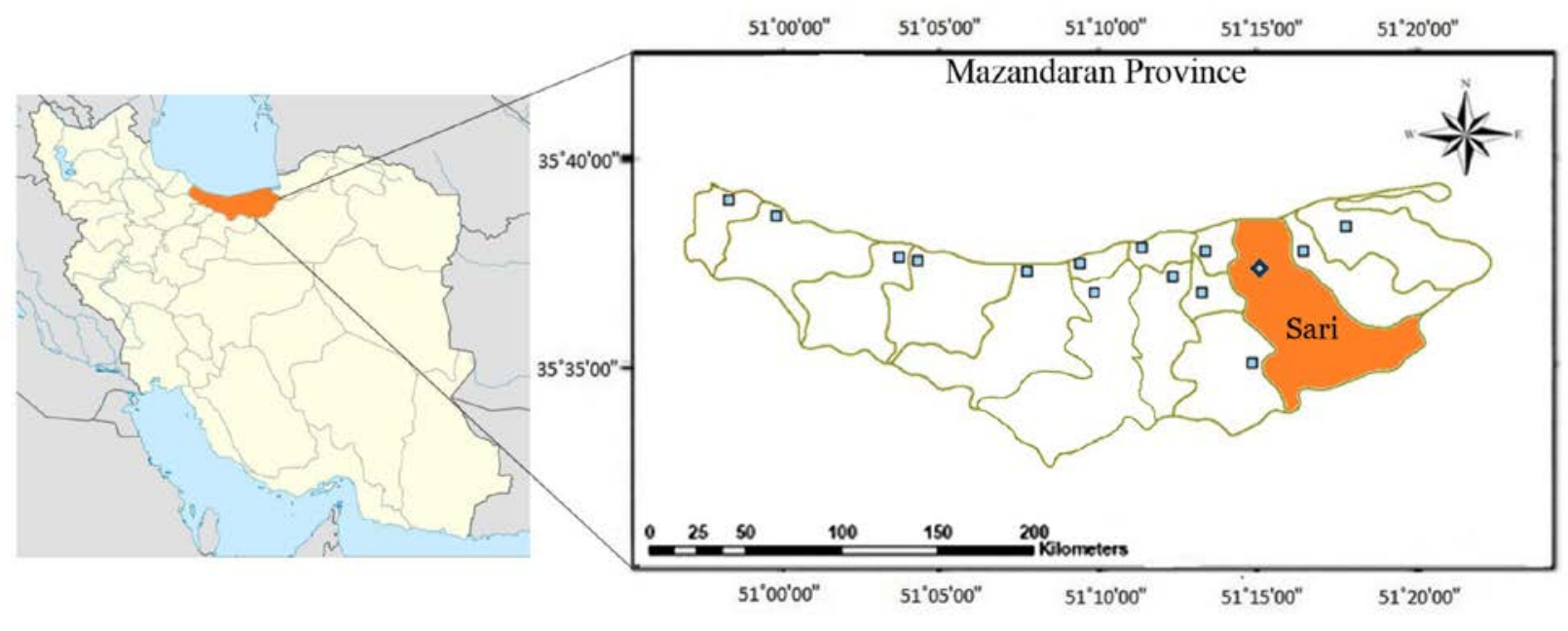

Fig. 1 Location of the study area 